\title{
Diagnóstico, classificação e monitoramento de leucemias baseado em espectroscopia
}

\author{
Raman \\ Diagnosis, classification and monitoring of leukemia based on Raman spectroscopy \\ Diagnóstico, clasificación y seguimiento de la leucemia basado en espectroscopia Raman
}

Recebido: 11/10/2021 | Revisado: 16/10/2021 | Aceito: 23/10/2021 | Publicado: 25/10/2021

\author{
Ana Mara Ferreira Lima \\ ORCID: https://orcid.org/0000-0001-9039-7328 \\ Universidade Anhembi Morumbi, Brasil \\ E-mail: anamarafl@yahoo.com.br \\ Janyersson Dannys Pereira da Silva \\ ORCID: https://orcid.org/0000-0002-5600-1219 \\ Christus Faculdade do Piauí, Brasil \\ E-mail: janyersondannys@gmail.com \\ Camila Ribeiro Daniel \\ ORCID: https://orcid.org/0000-0002-8180-9527 \\ Universidade Anhembi Morumbi, Brasil \\ E-mail: camiladaniel1206@gmail.com
}

\begin{abstract}
Resumo
O diagnóstico, classificação e monitoramento de leucemia requerem o uso e a combinação de várias tecnologias geralmente envolvendo coloração e exame da morfologia das células em uma amostra de sangue ou detecção seletiva de antígenos específicos da membrana celular. A espectroscopia Raman é uma técnica óptica baseada no espalhamento inelástico de luz por moléculas e pode fornecer informações bioquímicas altamente específicas com mínimo ou nenhum pré-tratamento de amostra. Com base nisso o presente estudo teve como objetivo realizar uma revisão sistemática por meio do levantamento de picos e marcadores em estudos experimentais e clínicos acerca do emprego da espectroscopia Raman no diagnóstico e a classificação da leucemia. Com a análise dos estudos selecionados foi possível evidenciar um grande progresso nas pesquisas sobre a aplicabilidade da espectroscopia Raman no diagnóstico, em especial sobre a sua especificidade e sensibilidade, para garantir a diferenciação entre os quatro principais subtipos de leucemias: leucemia linfoide crônica (LLC), leucemia linfoide aguda (LLA), leucemia mieloide crônica (LMC) e leucemia mieloide aguda (LMA).
\end{abstract}

Palavras-chave: Espectroscopia Raman; Diagnóstico; Leucemia.

\begin{abstract}
The diagnosis, classification and monitoring of leukemia requires the use and combination of various technologies usually involving staining and examining the morphology of cells in a blood sample or selective detection of specific cell membrane antigens. Raman spectroscopy is an optical technique based on the inelastic scattering of light by molecules and can provide highly specific biochemical information with minimal or no sample pretreatment. Based on this, the present study aimed to carry out a systematic review through the survey of peaks and markers in experimental and clinical studies about the use of Raman spectroscopy in the diagnosis and classification of leukemia. With the analysis of the selected studies, it was possible to show great progress in research on the applicability of Raman spectroscopy in diagnosis, in particular on its specificity and sensitivity, to ensure the differentiation between the four main subtypes of leukemia: chronic lymphoid leukemia (CLL), acute lymphoid leukemia (ALL), chronic myeloid leukemia (CML) and acute myeloid leukemia (AML).
\end{abstract}

Keywords: Raman spectroscopy; Diagnosis; Leukemia.

\section{Resumen}

El diagnóstico, la clasificación y el seguimiento de la leucemia requiere el uso y la combinación de varias tecnologías que normalmente implican la coloración y el examen de la morfología de las células en una muestra de sangre o la detección selectiva de antígenos específicos de la membrana celular. La espectroscopia Raman es una técnica óptica basada en la dispersión inelástica de luz por las moléculas y puede proporcionar información bioquímica detallada con un pretratamiento mínimo o nulo de la muestra. En base a esto, el presente estudio tuvo como objetivo realizar una revisión sistemática a través del relevamiento de picos y marcadores en estudios experimentales y clínicos sobre la utilización de la espectroscopia Raman en el diagnóstico y clasificación de la leucemia. El análisis de los estudios seleccionados ha evidenciado un gran avance en la investigación sobre la aplicabilidad de la espectroscopia Raman en el diagnóstico, en particular en su especificidad y sensibilidad, para asegurar la diferenciación entre los cuatro 
principales subtipos de leucemia: leucemia linfoide crónica, leucemia linfoide aguda, leucemia mieloide crónica y leucemia mieloide aguda.

Palabras clave: Espectroscopia Raman; Diagnóstico; Leucemia.

\section{Introdução}

De acordo com o Instituto Nacional de Câncer (2019), as leucemias são caracterizadas como alteração patológicas nos glóbulos brancos, em especial na medula óssea, que pela grande pluralidade celular acabam sendo liberadas na corrente sanguínea. O nível de maturação celular e os seus tipos que se alteram estão diretamente correlacionados ao subtipo da doença. As mesmas podem ser divididas em dois grandes grupos: aguda e crônica e apresentam doze subtipos, sendo quatro os mais importantes: leucemia linfoide crônica (LLC), leucemia linfoide aguda (LLA), leucemia mieloide crônica (LMC) e leucemia mieloide aguda (LMA).

As leucemias linfoides são alterações ligadas à linhagem linfocítica das células sanguíneas, a etiologia da LLC geralmente está vinculada a uma alteração genética que impede o curso do ciclo celular e com isso impede a morte programada dos linfócitos B (Hallek, 2017), apresentando desenvolvimento mais lento e normalmente acarreta pacientes mais idosos. Já a LLA é o câncer mais comum em crianças, muito relacionado com alterações genéticas, tais como translocação t(12;21) que gera a fusão TEL-AML1 e mutações nos genes relacionados à via regulatória HOX, seja de forma direta, como translocações no gene MLL, quanto de forma indireta com mutações nos cofatores da rota, juntamente com isso, as LLA tem grande potencial de recidivas (Pui et al., 2004; Hunger \& Mullinghan, 2015).

As leucemias mieloides são ligadas às mutações na linhagem mielocítica das células sanguíneas, sendo a LMC caracterizada pela translocação balanceada entre os genes ABL1 e BCR, t(9;22)(q34;q11.2). Essa alteração é conhecida como cromossomo Filadélfia, e por ser uma mutação exclusiva é utilizada como critério de diferenciação das demais leucemias através da pesquisa desta translocação (Jabbour \& Kantarjian, 2018). A LMA é dita como uma infiltração das células promielocíticas não diferenciadas ou com uma diferenciação inadequada na medula óssea; apresenta uma etiologia heterogênea (Döhner; Weisdorf \& Bloomfield, 2015).

Quando analisada a sua distribuição da LMA no Brasil, ela é mais comum nas regiões Norte e Nordeste, ocupando quinto e sétimo lugar de doença mais incidente, respectivamente, com estimativa de 249 mil casos em homens e 187 mil em mulheres até 2022 (INCA, 2019). Por conta disso a sua investigação deve ser feita da forma mais prática e rápida possível, já que um diagnóstico precoce está diretamente relacionado a um tratamento bem-sucedido, as técnicas atualmente utilizadas para diagnóstico diferencial dos tipos de para a leucemia utilizam a amostra de pulsão medular para pesquisa de alterações moleculares, morfológicas e quantitativas nas células do tecido sanguíneo. Importante ressaltar que a análise da lâmina de mielograma à procura de células diferenciadas é essencial e indispensável para o diagnóstico adequado dos pacientes (Azad et al., 2015; Managó; Zito \& De Luca, 2018; Naz et al., 2019).

Uma técnica que recentemente tem sido estudada para o diagnóstico diferencial das leucemias foi a espectroscopia Raman, que utiliza amostras de plasma para sua execução, essa técnica se relaciona na determinação morfológica das células. A espectroscopia Raman funciona através do espalhamento inelástico de radiação por moléculas polarizadas por um feixe de luz e com isso há uma reação de vibração das moléculas permitindo a formação de uma "imagem" através dos espectros gerados, esses picos são correspondentes aos componentes químicos da célula e com eles se consegue diferenciar de forma específica a fase de maturação que as células se encontram, em especial quando há uma associação com a técnica de espalhamento Raman intensificado por superfície (SERS) (Managó; Zito \& De Luca, 2018; Bai et al., 2020).

Uma técnica derivada do Raman é a utilização espectro em conjunto com a análise do espalhamento por superfície, que consegue fazer a diferenciação das moléculas das células de maneira isoladas e juntamente com isso há uma intensificação 
da sensibilidade por conta da excitação utilizada na metodologia, deixando-a mais adepta para uso na parte biológica (Zong et al., 2018). Outro método também derivado é a Raman com deslocado espacial que aumenta a sua capacidade de penetração em tecidos biológicos e materiais turvos em até $5 \mathrm{~cm}$, dando uma nova perspectiva para a investigação dos cânceres (Nicolson et al., 2021).

A proposta de utilização desta metodologia vem para tentar acelerar o processo de diagnóstico, podendo ser utilizada em momentos iniciais da doença e de forma ainda mais específica, já que com a técnica Raman tem-se a possibilidade de determinação específica de picos de proteínas, ácidos nucleicos e lipídios relacionados aos subtipos das leucemias, assim como pode ser utilizado para acompanhamento de tratamentos, levantando a possibilidade da utilização do Raman nas etapas de diagnóstico e acompanhamento de prognóstico (Managó; Zito \& De Luca, 2018).

Dessa forma, o presente estudo teve como objetivo realizar de forma sistemática (síntese qualitativa) o levantamento de evidências em estudos experimentais (ex vivo/in vitro) e clínicos buscando trazer uma síntese da utilização da espectroscopia Raman no diagnóstico de leucemias.

\section{Metodologia}

\subsection{Estratégia de busca}

Os estudos foram rastreados a partir das bases de dados eletrônicos SCOPUS, PubMed, Web of Science e Science Direct no período de Outubro de 2020 a Fevereiro de 2021, empregando descritores de pesquisa que incluem "Raman spectroscopy", "leukemia" e "blood cancer" combinado com "Raman scattering". As publicações que continham no título, resumo ou nas palavras-chave os termos descritos acima foram lidos na integra para a verificação se eles se adequavam ao estudo.

\subsection{Seleção dos estudos para inclusão na revisão sistemática}

Os estudos obtidos das bases de dados foram incluídos na revisão sistemática caso cumprissem os seguintes critérios: a) o estudo foi experimental ex vivo/in vivo; b) o estudo foi clínico; c) o método de estudo incluiu a utilização de qualquer tipo de espectroscopia Raman; d) o método de estudo indicou as linhagens de células/população empregadas; e) o estudo apontou os resultados dos elementos bioquímicas que diferenciaram as leucemias associados a utilização da espectroscopia Raman em diferentes tipos de leucemia. Todos os artigos que não se encaixavam nesses critérios foram excluídos, assim como artigos duplicados, revisões bibliográficas, editoriais, cartas, teses e dissertações.

\subsection{Extração de dados}

Os dados de cada publicação que preencheram os critérios de inclusão foram extraídos quanto ao: sobrenome do primeiro autor, ano de publicação, amostra do estudo, população, principais resultados obtidos, comparação e desfecho da pesquisa descrevendo alterações bioquímica, diferenciação de leucemias etc.

\section{Resultados e Discussão}

Na busca realizadas nas quatro bases de dados: SCOPUS, PubMed, Web of Science e Science Direct usando os descritores em conjunto foram encontrados um total de 639 artigos, que após uma filtragem utilizando os critérios de inclusão e exclusão de acordo com o fluxograma mostrado na Figura 1 totalizaram 29 artigos. Com uma distribuição temporal variando, principalmente de 2008-2020, com um artigo anterior de 1984, tendo o maior número de publicações em 2015 (Figura 2). 
Research, Society and Development, v. 10, n. 14, e67101421657, 2021

(CC BY 4.0) | ISSN 2525-3409 | DOI: http://dx.doi.org/10.33448/rsd-v10i14.21657

Figura 1: Fluxograma da filtragem dos artigos.

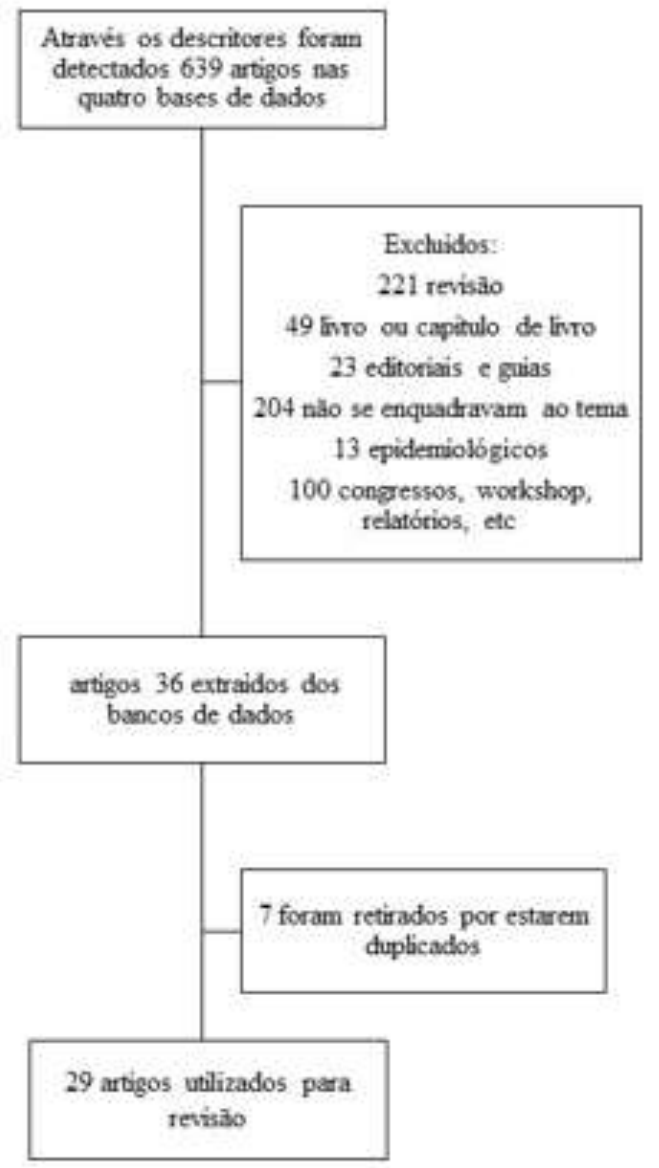

Fonte: Pesquisadores 2021.

Figura 2: Distribuição temporal dos 29 artigos coletados.

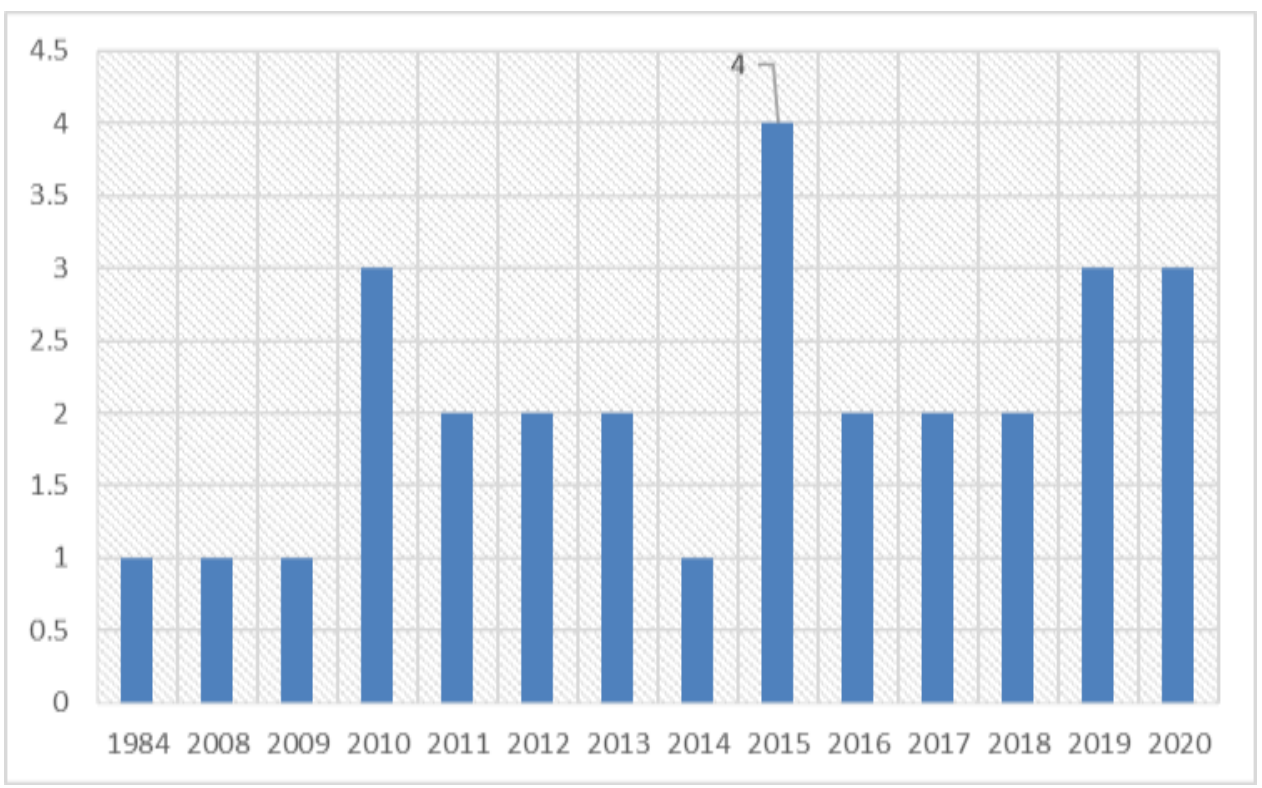

Fonte: Pesquisadores (2021).

Nesta revisão, destacamos a capacidade da espectroscopia Raman em determinar os subtipos de células de leucemia, avaliando a diferenciação e detectando os estágios da doença. A espectroscopia Raman é uma técnica espectroscópica 
vibracional que fornece informações detalhadas sobre a composição química e molecular de células e tecidos. Quando a luz do laser incidente atinge uma amostra de tecido, alguns de seus fótons sofrem uma mudança na energia, conhecida como efeito Raman (Tabela 1).

Tabela 1: Efeito Raman e suas atribuições na leucemia

\begin{tabular}{|c|c|c|}
\hline Autor/Ano & Picos utilizados & Atribuição na leucemia \\
\hline Plouvier, Huong, 1984 & Entre 240 e $300 \mathrm{~cm}^{-1}$ & $\begin{array}{l}\text { A análise dos espectros sugere estados de oxidação na } \\
\text { leucemia }\end{array}$ \\
\hline Chan et al., 2008 & $\begin{array}{l}678,785,1093,1126,1337 \\
1373, \quad 1447, \quad 1575, \quad 1605 \\
1615 \text { e } 1650 \mathrm{~cm}^{-1}\end{array}$ & $\begin{array}{l}\text { Mostrou a capacidade de discriminar células normais e } \\
\text { leucêmicas de diferentes indivíduos. }\end{array}$ \\
\hline Chan et al., 2009 & $785,1230,1305,1660 \mathrm{~cm}^{-1}$ & $\begin{array}{l}\text { Marcadores Raman específicos comumente atribuídos a } \\
\text { vibrações de DNA, RNA, proteína e lipídios em células } \\
\text { de mamíferos, sendo marcadores importantes para } \\
\text { discriminar linfócitos normais e cancerígenos. }\end{array}$ \\
\hline Neugebauer et al., $2010^{\mathrm{a}}$ & $\begin{array}{l}1621,1584,1564,1374 \mathrm{e} \\
755 \mathrm{~cm}^{-1}\end{array}$ & $\begin{array}{l}\text { Separação das células tumorais circulantes dos } \\
\text { leucócitos saudáveis. }\end{array}$ \\
\hline Neugebauer et al., $2010^{\mathrm{b}}$ & $\begin{array}{l}1580, \quad 1480, \quad 1640 . \quad 1373, \\
1345,1390, \\
710 \text { e } 502 \mathrm{~cm}^{-1}\end{array}$ & $\begin{array}{l}\text { A diferenciação bem-sucedida de células tumorais de } \\
\text { células sanguíneas saudáveis de maneira não destrutiva }\end{array}$ \\
\hline Nguyen et al., 2010 & $1616 \mathrm{~cm}^{-1}$ & $\begin{array}{l}\text { Detecção de marcadores de superfície de células de } \\
\text { leucemia linfocítica crônica usando nanopartículas de } \\
\text { ouro }\end{array}$ \\
\hline Dochow et al., 2011 & $\begin{array}{l}1002,1374,1564,1584 \mathrm{e} \\
1621 \mathrm{~cm}^{-1}\end{array}$ & $\begin{array}{l}\text { Análise discriminante linear para diferenciar eritrócitos, } \\
\text { leucócitos, células de leucemia mielóide aguda }\end{array}$ \\
\hline Poplineau et al., 2011 & $\begin{array}{l}720-725 ; 785 ; 1093-1094 \\
1315-1320 ; \text { e } 1575 \mathrm{~cm}^{-1}\end{array}$ & $\begin{array}{l}\text { Discerniu células leucêmicas tratadas com inibidor de } \\
\text { histona desacetilase do controle com alta confiança. }\end{array}$ \\
\hline Le Roux et al., 2012 & $\begin{array}{l}830-1093, \quad 1490, \quad 1579 \\
\sim 1658, \sim 1607 \mathrm{e} \sim 1255 \mathrm{~cm} \\
-1\end{array}$ & $\begin{array}{l}\text { Sugeriu que a extração de proteínas e fusão de DNA } \\
\text { ocorrem nas células durante o tratamento com os } \\
\text { extratos etanólicos, alterando drasticamente o conteúdo } \\
\text { molecular das células. }\end{array}$ \\
\hline Ong, Lim, Liu, 2012 & $734,1650,1011$ e $1672 \mathrm{~cm}^{-1}$ & $\begin{array}{l}\text { Mediu e analisou os diferentes modos de morte de } \\
\text { células leucêmicas individuais em suspensão. }\end{array}$ \\
\hline MacLaughlin et al., 2013a & $1618 \mathrm{~cm}^{-1}$ & $\begin{array}{l}\text { Marcação de três marcadores de superfície celular de } \\
\text { interesse em células B malignas da linha de células de } \\
\text { linfoma LY10. }\end{array}$ \\
\hline MacLaughlin et al., $2013^{\mathrm{b}}$ & Não informado & $\begin{array}{l}\text { Marcação de moléculas de CD20 em células de } \\
\text { leucemia linfocítica crônica }\end{array}$ \\
\hline González-Solís et al., 2014 & $1.002,1.160 \mathrm{e} 1.523 \mathrm{~cm}^{-1}$ & $\begin{array}{l}\text { Monitoramento do tratamento da leucemia por } \\
\text { quimioterapia para distinguir entre soro sanguíneo } \\
\text { normal e leucêmico e identificar os diferentes tipos de } \\
\text { leucemia com base na bioquímica sérica }\end{array}$ \\
\hline Happilon et al., 2015 & $\begin{array}{l}700-800,1010 \\
1665,1258 \mathrm{e} \\
1342 \mathrm{~cm}^{-1}\end{array}$ & $\begin{array}{l}\text { Diagnóstico de leucemia linfocítica crônica em } \\
\text { esfregaços de sangue não corados }\end{array}$ \\
\hline Khetani et al., 2015 & $\begin{array}{l}1032,1318,650,789,1003, \\
1032,1093,1119,1283, \\
1318,1436 \mathrm{~cm}^{-1}\end{array}$ & $\begin{array}{l}\text { Diferenciação sensível para monitorar e detectar células } \\
\text { de leucemia e diferenciação de células apoptóticas, } \\
\text { vivas e necróticas }\end{array}$ \\
\hline Vanna et al., 2015 & $\begin{array}{l}665,755,1249,1173,1249 \\
1366,1397,1540,1610 \mathrm{~cm}^{-1}\end{array}$ & $\begin{array}{l}\text { Identificação de células típicas de leucemia mieloide } \\
\text { aguda e síndrome mielodisplásica }\end{array}$ \\
\hline Zhang et al., 2015 & $\begin{array}{l}728,786,827,1003,1102, \\
1257,1340,1450,1660 \\
\mathrm{~cm}^{-1}\end{array}$ & $\begin{array}{l}\text { Espectro Raman revelou a parada do ciclo celular de } \\
\text { apoptose de linfócitos } \mathrm{T} \text { leucêmicos induzida por } \\
\text { triptólidos }\end{array}$ \\
\hline Fazio et al., 2016 & $1450 \mathrm{~cm}^{-1}$ & $\begin{array}{l}\text { Analisadas para abordar os efeitos, incluindo necrose e } \\
\text { apoptose, induzidos pelo estresse do envelhecimento }\end{array}$ \\
\hline Managò et al., 2016 & $\begin{array}{l}\begin{array}{l}700-800,1120,1370,1577 \\
\mathrm{~cm}^{-1}\end{array} \\
\end{array}$ & $\begin{array}{l}\text { Diagnóstico, classificação e acompanhamento de } \\
\text { leucemia linfoblástica aguda de células B }\end{array}$ \\
\hline Hassoun et al., 2017 & $\begin{array}{l}660,900,1376,723,1339 \\
800,960,2872,2923 \text { e } 2952 \\
\mathrm{~cm}^{-1}\end{array}$ & $\begin{array}{l}\text { Um chip microfluídico baseado em gotículas como uma } \\
\text { plataforma para a identificação de células lisadas de } \\
\text { leucemia }\end{array}$ \\
\hline Su et al., 2017 & $875-880 \mathrm{~cm}^{-1}$ & $\begin{array}{l}\text { Revelou células-tronco mesenquimais que inibem o } \\
\text { crescimento de células HL60 }\end{array}$ \\
\hline Managò et al., 2018 & $745, \quad 1120, \quad 1310, \quad 1337$, & Identificação de células hematopoéticas normais e \\
\hline
\end{tabular}


Research, Society and Development, v. 10, n. 14, e67101421657, 2021

(CC BY 4.0) | ISSN 2525-3409 | DOI: http://dx.doi.org/10.33448/rsd-v10i14.21657

\begin{tabular}{|c|c|c|}
\hline & 1370 e $1577 \mathrm{~cm}^{-1}$ & leucêmicas \\
\hline Silva et al., 2018 & 400 a $1800 \mathrm{~cm}^{-1}$ & $\begin{array}{l}\text { Modelo espectral para diagnóstico de leucemias agudas } \\
\text { em sangue total e plasma }\end{array}$ \\
\hline Féré et al., 2019 & $745,813,840$ e $1100 \mathrm{~cm}^{-1}$ & $\begin{array}{l}\text { Classificação em diferentes condições clínicas para } \\
\text { aplicação ao diagnóstico de leucemia linfocítica crônica }\end{array}$ \\
\hline González-Solís, 2019 & $1040-1654 \mathrm{~cm}^{-1}$ & $\begin{array}{l}\text { Discriminação entre câncer de mama, leucemia, câncer } \\
\text { cervical com base em espectroscopia Raman de } \\
\text { amostras de soro sanguíneo }\end{array}$ \\
\hline Rygula et al., 2019 & $\begin{array}{l}790,1100,1376-1344,1580 \\
1660 \text { e } 1252-1265 \mathrm{~cm}^{-1}\end{array}$ & $\begin{array}{l}\text { Destacou a heterogeneidade bioquímica de eosinófilos } \\
\text { humanos versus linha celular de leucemia eosinofílica } \\
\text { humana }\end{array}$ \\
\hline Bai et al., 2020 & $1445-1655 \mathrm{~cm}^{-1}$ & $\begin{array}{l}\text { Estudou as características de impressão digital de } \\
\text { leucemia linfocítica crônica e linfoma difuso de grandes } \\
\text { células B }\end{array}$ \\
\hline Dai et al., 2020 & $\begin{array}{l}623,646,728,748,783, \\
853,936,1004,1033,1099, \\
1126,1211,1256,1303, \\
1446 \text { e } 1658 \mathrm{~cm}^{-1}\end{array}$ & $\begin{array}{l}\text { Caracterização intrínseca entre células tumorais } \\
\text { malignas e leucócitos humanos normais }\end{array}$ \\
\hline Xie et al., 2020 & ${ }_{-1}^{854,1657,1667 \text { e } 1681 \mathrm{~cm}}$ & $\begin{array}{l}\text { Exploração in situ de Chidamida, um inibidor de histona } \\
\text { desacetilase, induz alterações moleculares de apoptose } \\
\text { de linfócitos T leucêmicos }\end{array}$ \\
\hline
\end{tabular}

Fonte: Pesquisadores (2021).

Excitações moleculares e interações entre as moléculas da amostra causam essa mudança e levam ao espalhamento de fótons. Um espectrômetro conta fótons espalhados e mede a intensidade e a mudança de energia da luz resultante em unidades por centímetro. Como cada molécula possui vibrações únicas, o espectro Raman do tecido consistirá em uma série de bandas ou picos, característicos da composição bioquímica daquele tecido (Plouvier \& Huong, 1984; Dochow et al., 2011; Managò et al., 2018; Xie et al., 2020).

Para melhor compreensão dos dados é importante ressaltar que os tipos de estudos escolhidos variaram entre estudos experimentais ex vivo e in vitro e ensaio clínicos, com uma soberania de estudo utilizando cultura celular pela praticidade e menor burocracia que pesquisas clínicas. O estudo obteve um total de 17 (59\%) estudos in vitro, 10 (34\%) clínicos e 2 (7\%) ex vivos (Figura 3), será abordado cada um dos tipos de estudo de forma individual (in vitro, ex vivo ou ensaio clínico), fazendo um agrupado dos seus dados.

Figura 3: Distribuição dos tipos de estudo.

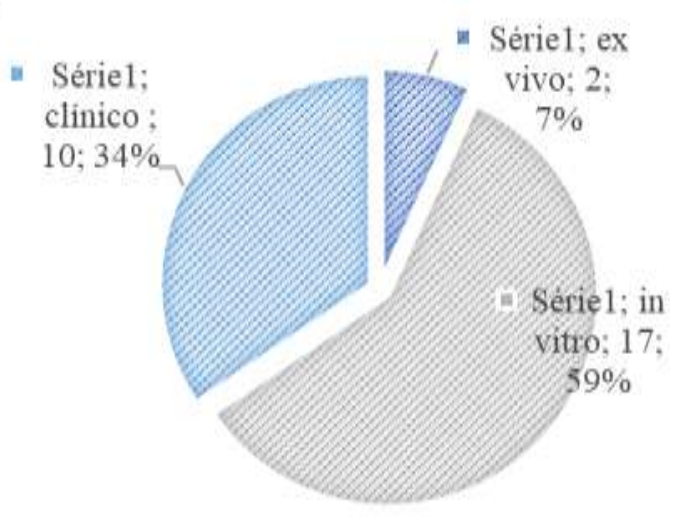

Fonte: Pesquisadores (2021).

O primeiro tipo de estudo analisado foi o ex vivo, que foram os estudos de Plouvier e Huong (1984) e Rygula et al. (2019), o primeiro estudo trouxe as amostras de 2 pacientes com leucemia, enquanto o segundo trouxe em seus resultados a 
quantidade de células que foram analisadas para obtenção da sua detecção do câncer, ambos conseguiram realizar a diferenciação das células oncológicas e o estudo de Rygula et al. (2019) ainda as separou das células saudáveis.

Os in vitro forma os que mais contabilizaram com 59\% dos estudos extraídos, para esse tipo de estudo são contabilizadas células que foram analisadas pela espectroscopia Raman, porém 10 estudos não informaram o seu quantitativo e apenas 7 trouxeram. Outro falou, já mencionado, foi a variabilidade de linhagens celulares utilizadas nos estudos, foi observado um total de 16 linhagens ATCC e 1 linhagem primária, sendo a mais prevalente a linhagem de célula Jurkat (leucemia de células T), seguida da OCI-AML3 (leucemia mieloide aguda). as linhagens de MN60, HL-60 e U-937 apareceram em dois estudos cada uma, as demais linhagens apareceram em apenas um estudo (CMSP, JM1, NC-37, MOLT-4, K562, LY10, MON-MAC-6, L2-blast, RS4;11, REH e, THP1).

Os estudos in vitro se dividiram basicamente em três objetivos, desenvolvimento de uma técnica de detecção, determinação efeito de um tratamento sob as células ou se a espectroscopia conseguia distinguir as células leucêmicas das demais comparadas. Dos 17 estudos: 10 demonstraram a capacidade de diferenciação das células leucêmicas, 4 traziam efeitos observados sob um tratamento específico e 3 eram desenvolvimento de novas técnicas (Figura 4).

A capacidade de detectar de forma não destrutiva e classificar de uma forma completamente livre de rótulos subconjuntos distintos de leucócitos é significativa tanto para estudos in vivo quanto in vitro do sistema imunológico em que uma técnica que fornece informações bioquímicas sem rótulo sobre o tipo de leucócito e o estado bioquímico pode ser muito útil para dar suporte a hemogramas não específicos padrão, foi nesse sentido que Managò et al. (2018) demonstrou que a espectroscopia Raman pode identificar e classificar com sucesso uma série de subgrupos de leucócitos importantes (granulócitos, monócitos e linfócitos).

Figura 4: Diferenciação dos objetivos dos estudos in vitro.

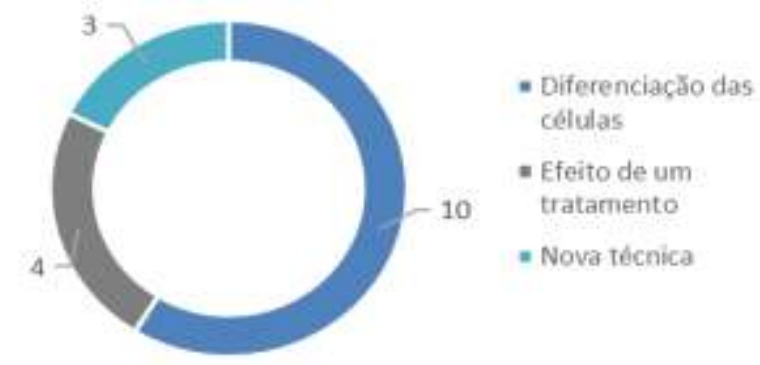

Fonte: Pesquisadores (2021).

O último tipo de estudo avaliado foram os ensaios clínicos, que totalizaram 10 estudos, 7 deles traziam número amostral detalhado, que no final totalizaram uma amostra de 405 pessoas, 139 voluntários saudáveis e 266 pacientes com leucemia (Figura 5), os estudos de Nguyen et al. (2010), MacLaughlin et al. (2013 ) e Dai et al. (2020) não trouxeram dados quantitativos as amostras usadas, porém todos os estudos tiveram como objetivo detecção específica das células leucêmicas. $\mathrm{O}$ estudo de Silva et al. (2018) ainda trouxe a diferença de sensibilidade quando a amostra utilizada era sangue total ou plasma, tendo uma melhor detecção quando se utilizava plasma.

A pesquisa apresentada por Vanna et al. (2015) relatou a caracterização de células que geralmente são avaliadas por hematopatologistas para o diagnóstico de leucemia mielóide aguda e síndrome mielodisplásica por meio de microespectroscopia Raman. Outros estudos já relataram a diferenciação baseada em Raman de células hematopoéticas (por exemplo, Chan et al (2008) caracterizaram e distinguiram linfócitos T e B de pacientes afetados por leucemia linfoblástica 
aguda; Neugebauer et al $\left(2010^{\text {a }}\right)$ estudaram e separaram células AML em cultura (OCI-AML) de outras células cancerosas em cultura e células normais de sangue humano).

Figura 5: Distribuição quantitativa dos subtipos de leucemia dos estudos clínicos.

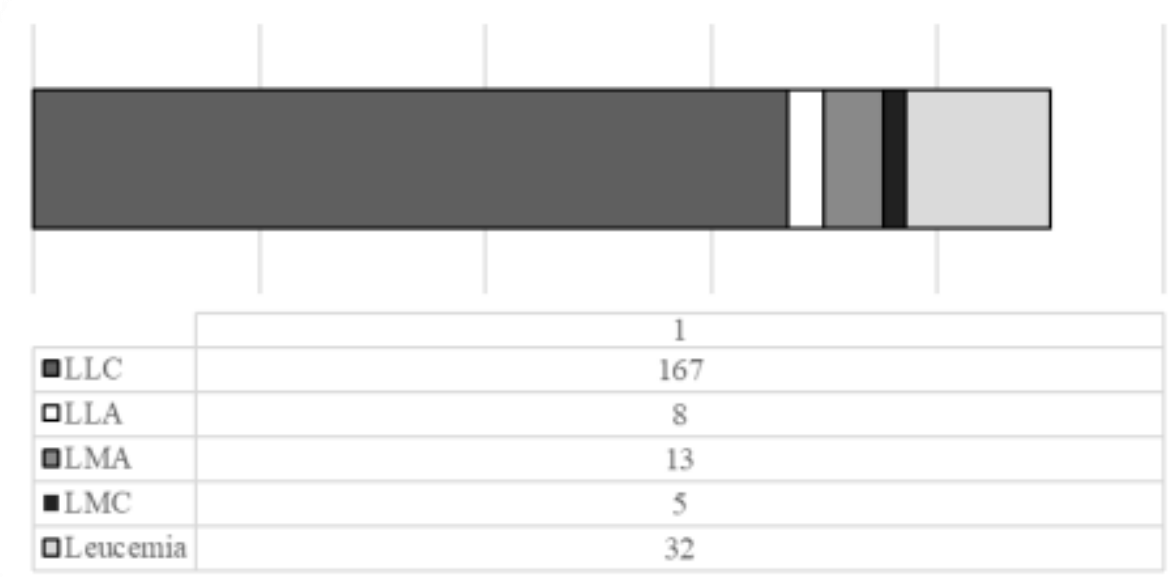

Fonte: Pesquisadores (2021).

Sobre os subtipos de cânceres observados nos estudo clínicos, temos a leucemia linfoide aguda (LLA), leucemia linfoide crônica (LLC), leucemia mieloide aguda (LMA), leucemia mieloide crônica (LMC) e leucemia sem estar específicada. No geral a LLC foi mais abordada em mais artigos $(n=5)$, seguida da LMA ( $n=3)$, LLA e LMC apareceram em 2 artigos cada e apenas um artigo abordou de forma generalizada as leucemias, artigos que analisaram mais de uma leucemia foram contatos mais de uma vez, como no caso de González-Solís et al. (2014), que trouxe amostras de LLA, LMA e LMC.

No estudo de González-Solís et al. (2014) a espectroscopia Raman foi usada para destacar as diferenças na composição química das amostras de soro de pacientes com diagnóstico clínico de leucemia versus controles saudáveis, um total de 144 espectros foram coletados com 102 espectros de 21 pacientes controle e 42 espectros de 7 pacientes com leucemia, permitindo identificar dois grandes grupos correspondentes a pacientes saudáveis e leucêmicos, e dentro do grupo leucêmico foi possível identificar os pacientes com LLA, LMA e LMC. A pesquisa demostrou que a espectroscopia Raman é uma ferramenta com um forte potencial de suporte para as técnicas atuais para detectar e identificar os diferentes tipos de leucemia com base em alterações de sondagem em nível molecular.

Em contraste Khetani et al. (2015) demonstrou uma plataforma robusta e sensível para monitorar e detectar células de leucemia, tal esquema usou nanopartículas e fibra de cristal fotônico de núcleo oco para aumentar o sinal Raman fraco de células de leucemia, obtendo um aprimoramento usando este esquema os autores também aplicaram a análise estatística de componentes principais para diferenciar células apoptóticas, vivas e necróticas, observando diferentes contagens de células, demonstrando a capacidade do sensor de detectar contagens de células mais baixas.

Observando a proposta demonstrada por Féré et al. (2019) foi percebido que as variações nas bandas do citocromo c revelaram uma aceleração metabólica das células leucêmicas que se dividem anarquicamente ou mostram disfunção no nível de apoptose, os autores mostraram que as bandas de DNA, proteína e citocromo c podem ser marcadores bioquímicos que discriminam entre estados saudáveis e doentes. Esses resultados estão de acordo com o estudo de Poplineau et al (2011), onde os autores mostraram que a espectroscopia Raman é capaz de distinguir células saudáveis de células cancerosas por condensação de DNA ou modificações de proteínas.

Tais estudos também corroboram com Ong; Lim e Liu (2012) nos quais foi demonstrado a técnica espectroscópica Raman simples para medir e analisar os diferentes modos de morte de células leucêmicas individuais em suspensão. A 
comparação da precisão da classificação de morte celular entre análise de componentes principais e análise de componentes bioquímicos foi realizada usando análise discriminante linear com base em recursos extraídos nesses dois métodos. Ambos os métodos apresentaram excelente desempenho na classificação de células vivas, apoptóticas e necróticas com 100\% de precisão uma combinação de coeficientes de ajuste de proteínas, DNA e lipídios.

A técnica Raman permite investigar células vivas únicas em seu ambiente natural e avaliar sua estrutura bioquímica: proteínas, lipídios e DNA podem ser visualizados de acordo com seus espectros vibracionais evitando o uso de marcadores ou a coloração celular antes da análise. Como os sinais Raman não são perturbados pela água, as células vivas podem ser analisadas em seu ambiente aquoso em condições fisiológicas, portanto, Raman é geralmente preferido em vez de, por exemplo, a espectroscopia de IV (Su et al., 2017; Managò et al., 2018).

Em contrapartida Silva et al. (2018) utilizou a espectroscopia Raman em amostras de sangue total e plasma para identificar diferenças espectrais entre indivíduos saudáveis e pacientes com leucemia aguda com base em seus componentes bioquímicos (proteínas, aminoácidos, carboidratos, lipídios e carotenóides) onde extraiu as informações mais significativas (com base na variância) de um conjunto de dados original, gerando duas novas variáveis, chamadas vetores de carregamento de componentes principais. O modelo de discriminação baseado em mínimos quadrados parciais aplicados ao espectro de sangue total mostrou superioridade na discriminação do grupo saudável do leucêmico em relação ao plasma, com sensibilidade de $91,9 \%$, especificidade de $100 \%$ e acurácia de $96,5 \%$.

A espectroscopia Raman tem o potencial de monitorar essas mudanças em nível molecular no estágio inicial, pois cada biomolécula dá origem a um pico distinto no espectro Raman e gera impressões digitais dessas moléculas e as diferenças espectrais entre amostras normais e doentes fornecem basicamente informações sobre anormalidades, que são utilizadas para fins de diagnóstico (Bai et al., 2020; Dai et al., 2020).

Já o trabalho proposto por Rygula et al. (2019) forneceu características morfológicas e bioquímicas baseadas em Raman de eosinófilos humanos, tanto de células primárias quanto da linhagem celular leucêmica, EoL-1. A imagem confocal Raman foi testada como uma ferramenta útil e rápida para caracterizar o conteúdo bioquímico localizado nas amostras. Esta técnica não invasiva e não destrutiva encontrou grande utilidade na análise de diferentes células sanguíneas, também a nível intracelular.

Entretanto, na pesquisa de Fazio et al. (2016) foi escolhida a linhagem celular U937 como modelo de leucemia, pois apresenta diversas características monocíticas, como diferenciação ou susceptibilidade à apoptose, fenômenos de secreção de citocinas e exposição de novos receptores, nesta pesquisa espectros Raman foram utilizados como dados de entrada para análise de componentes principais, a fim de detectar e classificar alterações espectrais entre as células U937 e correlacionado a um aumento significativo dos níveis de apoptose.

No estudo exploratório de Bai et al. (2020), os autores confirmaram que a análise de plasma baseada em espectroscopia Raman de linfoma é viável, sugerindo um papel potencial para espectroscopia Raman plasmática na deteç̧ão de leucemia linfocítica crônica e aplicações de triagem.

Nesse sentido demonstramos com a presente pesquisa que espectroscopia Raman como uma ferramenta sem rótulo para avaliar a fisiologia de células e tecidos percorreu um longo caminho nos últimos 30 anos, e especialmente a última década viu um crescimento quase exponencial de aplicações e metodologias relacionadas a este tópico como demonstrado na tabela 2.

O ganho de sensibilidade gerado por novas tecnologias e as ferramentas de análise multivariada mais avançadas, facilmente acessíveis e poderosas, como agrupamento de médias ou variações de análise de componente principal, tornaram-se padrão na análise e interpretação de grandes conjuntos de dados multidimensionais obtidos por imagem Raman espontânea ou imagem Raman coerente multiplexada (Xie et al., 2020).

Diante do exposto a Tabela 2 apresenta um compilado dos estudos demostrados acima: 
Tabela 2: Características extraídas dos estudos utilizados.

\section{Autor}

Plouvier \&

Huong, 1984

Chan et al.,

2008

Chan et al.,

2009

\section{Amostra}

Ex vivo: Sangue total de

pacientes com leucemia

\section{In vitro: Células}

mononucleadas de sangue periférico (CMSP)

In vitro: linhagens JM1,

NC-37 e Molt-4
População

2 pacientes

Não informado

Não informado

Não informado

\section{Resultado}

Observação da diferença de espectro das amostras

\begin{tabular}{ll}
\hline $\begin{array}{l}\text { Neugebauer et } \\
\text { al., } 2010^{\mathrm{a}}\end{array}$ & AMLtro: linhagem OCI-
\end{tabular}

\begin{tabular}{|c|c|c|c|}
\hline $\begin{array}{l}\text { Neugebauer et } \\
\text { al, } 2010^{\mathrm{b}}\end{array}$ & $\begin{array}{l}\text { In vitro: Linhagem OCI- } \\
\text { AML3 }\end{array}$ & $\begin{array}{l}8 \text { células } \\
\text { diferentes }\end{array}$ & $\begin{array}{l}\begin{array}{l}\text { Detecção das células leucêmicas nos picos } \\
\text { de } 1482,11235 \text { e } 1004\end{array} \\
\end{array}$ \\
\hline $\begin{array}{l}\text { Nguyen et al., } \\
2010\end{array}$ & $\begin{array}{l}\text { Clínico: Leucemia linfoide } \\
\text { crônica }\end{array}$ & Não informado & $\begin{array}{l}\text { Célula marcadas com nanopartículas anti-CD19 } \\
\text { conseguiram ser detectadas em } 11 \text { picos diferentes }\end{array}$ \\
\hline $\begin{array}{l}\text { Dochow et al., } \\
2011\end{array}$ & $\begin{array}{l}\text { In vitro: linhagem OCI- } \\
\text { AML3 }\end{array}$ & 75 células & $\begin{array}{l}\text { Similaridade nos picos da linhagem leucêmica e } \\
\text { leucócito }\end{array}$ \\
\hline $\begin{array}{l}\text { Poplineau et al., } \\
2011\end{array}$ & $\begin{array}{l}\text { In vitro: linhagem células } \\
\text { Jurkat }\end{array}$ & 333 células & $\begin{array}{l}\text { Detecção de picos específicos, especialmente para } \\
\text { o DNA e proteínas com Raman de pinça a laser }\end{array}$ \\
\hline $\begin{array}{l}\text { Le Roux et al., } \\
2012\end{array}$ & In vitro: linhagem U-937 & Não informado & $\begin{array}{lllll}\text { Identificação da linhagem } & \text { U-937 } & \text { por } & 4 \\
\text { parâmetros, totalizando } 7 \text { picos } & & & \end{array}$ \\
\hline $\begin{array}{l}\text { Ong; Lim \& } \\
\text { Liu, } 2012\end{array}$ & In vitro: linhagem K562 & 20 células & Detecção nos picos 1011,1672 e 1650 \\
\hline $\begin{array}{l}\text { MacLaughlin et } \\
\text { al., } 2013^{\mathrm{a}}\end{array}$ & $\begin{array}{l}\text { In vitro: linhagem LY10 e } \\
\text { primaria de leucemia } \\
\text { linfoide crônica }\end{array}$ & Não informado & $\begin{array}{l}\text { Detecção específica da linhagem com sondas de } \\
\text { nanopartículas de } \mathrm{Au}\end{array}$ \\
\hline $\begin{array}{l}\text { MacLaughlin et } \\
\text { al., } 2013^{\text {b }}\end{array}$ & $\begin{array}{l}\text { Clínico: leucemia linfoide } \\
\text { crônica }\end{array}$ & Não informado & $\begin{array}{l}\text { Determinação das células pela detecção de CD20 } \\
\text { através de nanopartículas de } \mathrm{Au} \text { conjugada com } \\
\text { rituximab }\end{array}$ \\
\hline
\end{tabular}

Utilização da espectroscopia Raman para análise celular através da marcação com partícula azul

Usada comparação entre espectro das células T e

B das amostras saudáveis e amostras leucêmicas, observando de diagnóstico positivo em 11 picos fixadas com metanol ou paraformaldeido com as não fixadas para realização da identificação, forma observados 7 picoss determinantes

\section{Comparação}

Células com e sem marcação com a partícula azul

Amostras saudáveis

Comparação entre as 3

linhagens

Linhagens tumorais,

leucócitos e eritrócitos

dáveis, eritrócitos e das outras linhagens tumorais usadas no estudo em 5 picos diferentes.

Detecção das células leucêmicas nos picos Comparação entre as linhagens

Células marcadas com anti-

\section{CD19 e anti-CD4}

Comparação com as demais

linhagens, leucócitos e eritrócitos

Desenvolvimento de uma nova metodologia para detecção

Comparação de linhagens tratadas e não tratadas

Determinação das células por morte celular

Desenvolvimento de uma nova metodologia para detecção

Desenvolvimento de uma

nova metodologia para detecção

\section{Desfecho}

2 pacientes positivos

Diferenciação específica do tumor

Diferenciação específica do tumor

\section{Diferenciação específica das} células tumorais

Diferenciação específica das células tumorais

Diferenciação específica das células tumorais

Detecção de 70 células de forma correta

226 tratadas com TSA e MS275 e 107 não tratadas

Diferenciação específica das células tumorais

Pico 734 para determinação da morte

Diferenciação específica das células tumorais

Diferenciação específica das células tumorais 
Research, Society and Development, v. 10, n. 14, e67101421657, 2021

(CC BY 4.0) | ISSN 2525-3409 | DOI: http://dx.doi.org/10.33448/rsd-v10i14.21657

\begin{tabular}{|c|c|c|c|c|c|}
\hline $\begin{array}{l}\text { González-Solís } \\
\text { et al., } 2014\end{array}$ & $\begin{array}{l}\text { Clínico: pacientes com } \\
\text { leucemia (três tipos) e } \\
\text { voluntários saudáveis }\end{array}$ & $\begin{array}{l}7 \text { pacientes e } 21 \\
\text { voluntários } \\
\text { saudáveis }\end{array}$ & 42 espectros diferentes para leucemias & Amostras saudáveis & $\begin{array}{l}\text { Diferenciação específica das } \\
\text { células tumorais }\end{array}$ \\
\hline $\begin{array}{l}\text { Happilon et al., } \\
2015\end{array}$ & $\begin{array}{l}\text { Clínico: pacientes com } \\
\text { leucemia linfocítica crônica } \\
\text { e voluntários saudáveis }\end{array}$ & $\begin{array}{l}49 \text { pacientes com } \\
\text { câncer e } 27 \\
\text { voluntários }\end{array}$ & $\begin{array}{l}\text { Detecção das células de LLC marcadas com May- } \\
\text { Grünwald Giemsa }\end{array}$ & Amostras saudáveis & $\begin{array}{l}88 \% \text { de eficiência para } \\
\text { identificação de saudáveis e } \\
91 \% \text { para células leucêmicas }\end{array}$ \\
\hline $\begin{array}{l}\text { Khetani et al., } \\
2015\end{array}$ & In vitro: linhagem HL-60 & Não informado & $\begin{array}{l}\text { Detecção das células leucêmicas usando Raman } \\
\text { com HC-PCF com nanopartículas Ag, detecção } \\
\text { nos picos de } 1032 \text { e } 1318 \text { com observação do } \\
\text { ciclo celular }\end{array}$ & $\begin{array}{l}\text { Desenvolvimento de uma } \\
\text { nova metodologia para } \\
\text { detecção }\end{array}$ & $\begin{array}{l}\text { Diferenciação específica das } \\
\text { células tumorais }\end{array}$ \\
\hline $\begin{array}{l}\text { Vanna et al., } \\
2015\end{array}$ & $\begin{array}{l}\text { Clínico: pacientes com } \\
\text { leucemia mieloide aguda e } \\
\text { síndrome mielodesplásica }\end{array}$ & $\begin{array}{l}7 \text { pacientes com } \\
\text { diferentes tipos de } \\
\text { LMA }\end{array}$ & Detecção obtida nos picos de 500 e 1800 & $\begin{array}{l}\text { Amostras saudáveis e } \\
\text { diferenciação entre LMA e } \\
\text { SMD }\end{array}$ & $\begin{array}{ll}\text { Diferenciação } & \text { dos tipos } \\
\text { celulares: } & \text { mieloblastos, } \\
\text { promielócitos, } & \text { promielócitos } \\
\text { anormais e eritroblastos }\end{array}$ \\
\hline $\begin{array}{l}\text { Zhang et al., } \\
2015\end{array}$ & In vitro: células Jurkat & $\begin{array}{l}10 \text { células } \\
\text { individuais }\end{array}$ & $\begin{array}{l}\text { Avaliação da morte celular a avaliando o ciclo } \\
\text { celular em } 9 \text { picos diferentes }\end{array}$ & Amostras saudáveis & $\begin{array}{l}\text { Diferenciação específica das } \\
\text { células tumorais }\end{array}$ \\
\hline $\begin{array}{l}\text { Fazio et al., } \\
2016\end{array}$ & In vitro: linhagem U937 & Não informado & Detecção obtida nos picos de 788 e 1095 & $\begin{array}{l}\text { Desenvolvimento de uma } \\
\text { nova metodologia para } \\
\text { detecção }\end{array}$ & $\begin{array}{l}\text { Diferenciação específica das } \\
\text { células tumorais }\end{array}$ \\
\hline $\begin{array}{l}\text { Managò et al., } \\
2016\end{array}$ & $\begin{array}{l}\text { In vitro: linhagem L2-blast, } \\
\mathrm{RS} 4 ; 11, \mathrm{REH}, \mathrm{MN} 60\end{array}$ & >300 células & $\begin{array}{l}\text { Identificação de espectros específicos para cada } \\
\text { um dos } 4 \text { tipos celulares. }\end{array}$ & $\begin{array}{l}\text { Comparação entre as } \\
\text { linhagens e com as células B }\end{array}$ & $\begin{array}{l}\text { Resultado com } 298 \text { células B } \\
\text { identificadas, } 283 \text { células } \\
\text { RS4;11, 286 células REH e } \\
300 \text { células MN60 }\end{array}$ \\
\hline $\begin{array}{l}\text { Hassoun et al., } \\
2017\end{array}$ & $\begin{array}{l}\text { In vitro: linhagem THP-1, } \\
\text { MONO-MAC-6 e célula } \\
\text { Jurkat }\end{array}$ & Não informado & $\begin{array}{l}\text { Mais especifico para MONO-MAC-6, em seguida } \\
\text { THP-1 e por último Jurkat com auxílio de } \\
\text { nanopartículas }\end{array}$ & $\begin{array}{l}\text { Comparação entre as } \\
\text { linhagens }\end{array}$ & $\begin{array}{l}\text { Diferenciação específica das } \\
\text { células tumorais }\end{array}$ \\
\hline Su et al., 2017 & In vitro: linhagem HL-60 & Não informado & Detecção específica em 7 picos diferentes & Sem comparação determinada & Avaliação de crescimento \\
\hline $\begin{array}{l}\text { Managò et al., } \\
2018\end{array}$ & In vitro: linhagem $\mathrm{MN} 60$ & 600 células & $\begin{array}{l}\text { Determinação de } 4 \text { picos específicas para a } \\
\text { linhagem tumoral }\end{array}$ & Amostra saudável & $\begin{array}{l}\text { Diferenciação específica: } 300 \\
\text { células B e } 296 \text { linhagem } \\
\text { MN60 }\end{array}$ \\
\hline $\begin{array}{l}\text { Silva et al., } \\
2018\end{array}$ & $\begin{array}{l}\text { Clínico: sangue e plasma } \\
\text { de pacientes com leucemia }\end{array}$ & $\begin{array}{l}38 \text { amostras } \\
\text { sangue total e } 40 \\
\text { amostras de } \\
\text { plasma }\end{array}$ & Determinação de pico específico: 830 & Amostra saudável & $\begin{array}{l}\text { Sensibilidade para plasma de } \\
95,7 \% \text {, especificidade de } 98 \% \\
\text { e acurácia de } 97,1 \% \text {. }\end{array}$ \\
\hline $\begin{array}{l}\text { Féré et al., } \\
2019\end{array}$ & $\begin{array}{l}\text { Clínico: pacientes com } \\
\text { leucemia linfoide crônica }\end{array}$ & $\begin{array}{l}61 \text { voluntários } \\
\text { saudáveis e } 79 \\
\text { pacientes }\end{array}$ & $\begin{array}{l}\text { Determinação de bandas associadas aos ácidos } \\
\text { nucleicos, proteínas e citocromo c das células } \\
\text { leucêmicas }\end{array}$ & Amostra saudável & $\begin{array}{l}\text { Detecção específica das células } \\
\text { leucêmicas }\end{array}$ \\
\hline
\end{tabular}


Research, Society and Development, v. 10, n. 14, e67101421657, 2021

(CC BY 4.0) | ISSN 2525-3409 | DOI: http://dx.doi.org/10.33448/rsd-v10i14.21657

\begin{tabular}{|c|c|c|c|c|c|}
\hline $\begin{array}{l}\text { González-Solís, } \\
2019\end{array}$ & Clínico: amostra de soro & 7 pacientes & $\begin{array}{l}\text { Associação do pico de } 1447 \text { na detecção da } \\
\text { leucemia }\end{array}$ & $\begin{array}{l}\text { Amostra de câncer de mama e } \\
\text { cervical }\end{array}$ & $\begin{array}{l}\text { Detecção específica das células } \\
\text { leucêmicas }\end{array}$ \\
\hline $\begin{array}{l}\text { Rygula et al., } \\
2019\end{array}$ & $\begin{array}{l}\text { Ex vivo: células isoladas de } \\
\text { amostras clínicas e } \\
\text { linhagem EoL-1 }\end{array}$ & 60 células & $\begin{array}{l}\text { Marcação de lipídeos, núcleo e citoplasma de } \\
\text { eosinófilos para diferenciação entre as células } \\
\text { derivados clínicos e de ATCC }\end{array}$ & $\begin{array}{l}\text { Eosinófilo derivado de } \\
\text { amostra da ATCC }\end{array}$ & $\begin{array}{l}\text { Detecção de picos específicos } \\
\text { para diferenciação entre as } \\
\text { origens }\end{array}$ \\
\hline Bai et al., 2020 & $\begin{array}{l}\text { Clínico: pacientes com } \\
\text { leucemia linfoide crônica }\end{array}$ & $\begin{array}{l}39 \text { pacientes e } 30 \\
\text { voluntários } \\
\text { saudáveis }\end{array}$ & $\begin{array}{l}\text { Desenvolvimento de nova parâmetro para a } \\
\text { amostra de sangue, usando os picos de } 1445 \text { e } \\
1655\end{array}$ & Amostra saudável & $\begin{array}{l}\text { Detecção específica das células } \\
\text { leucêmicas com sensibilidade } \\
\text { de } 92,86 \% \text { e especificidade de } \\
100 \%\end{array}$ \\
\hline Dai et al., 2020 & $\begin{array}{l}\text { Clínico: pacientes com } \\
\text { leucemia e voluntários } \\
\text { saudáveis }\end{array}$ & Não informado & $\begin{array}{l}\text { Determinação de } 17 \text { espectros possíveis para } \\
\text { detecção de células tumorais }\end{array}$ & Amostra saudável & $\begin{array}{l}94,43 \% \text { de especificidade na } \\
\text { detecção das células tumorais }\end{array}$ \\
\hline Xie et al., 2020 & $\begin{array}{l}\text { In vitro: linhagem células } \\
\text { Jurtak }\end{array}$ & Não informado & $\begin{array}{l}\text { Determinação da morfologia por } 2 \text { componentes } \\
\text { principais (PC): PC1 com } 15 \text { espectros e PC } 2 \text { com } \\
6\end{array}$ & $\begin{array}{l}\text { Comparação de linhagens } \\
\text { tratadas e não tratadas } \\
\text { (Chidamide ou SAHA ou MS- } \\
\text { 275) }\end{array}$ & $\begin{array}{l}\text { Diferenciação específica das } \\
\text { células tumorais e o tipo de } \\
\text { morte celular }\end{array}$ \\
\hline
\end{tabular}

Fonte: Pesquisadores (2021) 


\section{Conclusão}

Com a análise detalhadas dos 29 artigos foi possível observar um grande avanço nas pesquisas sobre a aplicabilidade da espectroscopia Raman no diagnóstico, em especial sobre a sua especificidade e sensibilidade, para garantir que a diferenciação entre os quatro principais subtipos de leucemias (LLC, LLA, LMC e LMA) sejam feitas de forma confiável, muitas vezes o ensaio era associado a sondas ou corantes para que as análises de picos fossem as mais precisas. Os estudos com pacientes confirmaram a eficiência da técnica para diagnóstico, dando uma maior credibilidade e bagagem para a sua consolidação junto aos protocolos clínicos num futuro próximo.

As informações reunidas no presente estudo podem fundamentar a realização de novas pesquisas para esse fim, o diagnóstico não invasivo de leucemias. Será de grande importância a criação de um banco de dados espectral, para servir de base comparativa na análise das amostras realizadas clinicamente. Ainda, a criação de uma tabela de picos dos elementos bioquímicos modificados pelo câncer a fim de agilizar o diagnóstico ou a determinação de possíveis alterações. Mais estudos envolvendo amostras sanguíneas fragmentadas, células e soro, contribuirão para a maior especificidade do diagnóstico.

\section{Agradecimentos}

A. M. F. Lima e C. R. Daniel agradecem à Coordenação pelo Aperfeiçoamento de Pessoal de Nível Superior (CAPES) pelas bolsas de Doutorado (Código Financeiro 001).

\section{Referências}

Azad, M. et al. (2015). Short view of leukemia diagnosis and treatment in Iran. International journal of hematology-oncology and stem cell research. 9(2), 88.

Bai, Y. et al. (2020). Raman spectroscopy-based biomarker screening by studying the fingerprint characteristics of chronic lymphocytic leukemia and diffuse large B-cell lymphoma. Journal of Pharmaceutical and Biomedical Analysis, 190, 113514.

Chan, J. W. et al. (2009). Nondestructive identification of individual leukemia cells by laser trapping Raman spectroscopy. Analytical chemistry, 80 (6), 21802187.

Chan, J. W.; Taylor, D. S. \& Thompson, D. L. (2009). The effect of cell fixation on the discrimination of normal and leukemia cells with laser tweezers Raman spectroscopy. Biopolymers: Original Research on Biomolecules, 91 (2), 132-139.

Dai, Y. et al. (2020). Intrinsic feature between malignant tumor cells and human normal leukocytes with statistical decision tree analysis via Raman spectroscopy. arXiv preprint arXiv:2011.14500.

Dochow, S. et al. (2011). Tumour cell identification by means of Raman spectroscopy in combination with optical traps and microfluidic environments. Lab on a Chip, 11(8), 1484-1490.

Döhner, H., Weisdorf, D. J. \& Bloomfield, C. D. (2015). Acute myeloid leukemia. New England Journal of Medicine, 373 (12), $1136-1152$.

Fazio, E. et al. (2016). A micro-Raman spectroscopic investigation of leukemic U-937 cells in aged cultures. Spectrochimica. Acta Part A: Molecular and Biomolecular Spectroscopy, 159, 21-29.

Féré, M. et al. (2020). Implementation of a classification strategy of Raman data collected in different clinical conditions: application to the diagnosis of chronic lymphocytic leukemia. Analytical and Bioanalytical Chemistry, 412 (4), 949-962.

González-Solís, J. L. (2019). Discrimination of different cancer types clustering Raman spectra by a super paramagnetic stochastic network approach. PloS One, 14 (3), e0213621.

González-Solís, J. L. et al. (2014). Monitoring of chemotherapy leukemia treatment using Raman spectroscopy and principal component analysis. Lasers in Medical Science, 29 (3), 1241-1249.

Hallek, M. (2017). Chronic lymphocytic leukemia: 2017 update on diagnosis, risk stratification, and treatment. American Journal of Hematology, 92 (9), 946965 .

Happillon, T. et al. (2015). Diagnosis approach of chronic lymphocytic leukemia on unstained blood smears using Raman microspectroscopy and supervised classification. Analyst, 140 (13), 4465-4472.

Hassoun, M. et al. (2018). A droplet-based microfluidic chip as a platform for leukemia cell lysate identification using surface-enhanced Raman scattering. Analytical and Bioanalytical Chemistry, 410 (3), 999-1006.

Hunger, S. P. \& Mullighan, C. G. (2015). Acute lymphoblastic leukemia in children. New England Journal of Medicine, 373 (16), $1541-1552$. 
INCA (Instituto Nacional de Câncer José Alencar Gomes da Silva) (2019). Estimativa 2020: incidência de câncer no Brasil / Instituto Nacional de Câncer José Alencar Gomes da Silva. INCA.

Jabbour, E. \& kantarjian, H. (2018). Chronic myeloid leukemia: 2018 update on diagnosis, therapy and monitoring. American Journal of Hematology, 93 (3), $442-459$.

Khetani, A. et al. (2015). Hollow core photonic crystal fiber for monitoring leukemia cells using surface enhanced Raman scattering (SERS). Biomedical Optics Express, 6 (11), 4599-4609.

Le Roux, K. et al. (2012) A micro-Raman spectroscopic investigation of leukemic U-937 cells treated with Crotalaria agatiflora Schweinf and the isolated compound madurensine. Spectrochimica Acta Part A: Molecular and Biomolecular Spectroscopy, 95, 547-554.

Maclaughlin, C. M. et al. (2013a). Surface-enhanced Raman scattering dye-labeled Au nanoparticles for triplexed detection of leukemia and lymphoma cells and SERS flow cytometry. Langmuir, 29 (6), 1908-1919.

Maclaughlin, C. M. et al. (2013b). Evaluation of SERS labeling of CD20 on CLL cells using optical microscopy and fluorescence flow cytometry. Nanomedicine: Nanotechnology, Biology and Medicine, 9 (1), 55-64.

Managò, S. et al. (2016). A reliable Raman-spectroscopy-based approach for diagnosis, classification and follow-up of B-cell acute lymphoblastic leukemia. Scientific Reports, 6 (1), 1-13.

Managò, S. et al. (2018). Raman detection and identification of normal and leukemic hematopoietic cells. Journal of Biophotonics, 11 (5), e201700265.

Managò, S; Zito, G. \& De Luca, A. C. (2018). Raman microscopy based sensing of leukemia cells: a review. Optics \& Laser Technology, 108, 7-16.

Naz, I. et al. (2019). Robust discrimination of leukocytes protuberant types for early diagnosis of leukemia. Journal of Mechanics in Medicine and Biology, 19 (6), 1950055.

Neugebauer, U. et al. (2010a). Towards detection and identification of circulating tumour cells using Raman spectroscopy. Analyst, 135 (12), $3178-3182$.

Neugebauer, U. et al. (2010b). Identification and differentiation of single cells from peripheral blood by Raman spectroscopic imaging. Journal of Biophotonics, 3 (8-9), 579-587.

Nguyen, C. T. et al. (2010). Detection of chronic lymphocytic leukemia cell surface markers using surface enhanced Raman scattering gold nanoparticles. Cancer Letters, 292 (1), 91-97.

Nicolson, F. et al. (2021). Spatially offset Raman spectroscopy for biomedical applications. Chemical Society Reviews.

Ong, Y. H.; Lim, M. \& Liu, Q. (2012). Comparison of principal component analysis and biochemical component analysis in Raman spectroscopy for the discrimination of apoptosis and necrosis in K562 leukemia cells. Optics Express, 20 (20), 22158-22171.

Plouvier, S. R. \& Huong, P. V. (1984). Microbial chromophore materials in circulating blood identified by laser micro Raman spectroscopy. Biorheology, 23 (s1), S345-S347.

Poplineau, M. et al. (2011). Raman microspectroscopy detects epigenetic modifications in living Jurkat leukemic cells. Epigenomics, 3 (6), $785-794$

Pui, C. H.; Relling, M. V. \& Downing, J. R. (2004). Acute lymphoblastic leukemia. New England Journal of Medicine, 350 (15), $1535-1548$.

Rygula, A. et al. (2019). Raman imaging highlights biochemical heterogeneity of human eosinophils versus human eosinophilic leukaemia cell line. British Journal of Haematology, 186 (5), 685-694.

Silva, A. M. et al. (2018). Spectral model for diagnosis of acute leukemias in whole blood and plasma through Raman spectroscopy. Journal of Biomedical Optics, 23 (10), 107002.

Su, X. et al. (2017). Raman spectrum reveals Mesenchymal stem cells inhibiting HL60 cells growth. Spectrochimica Acta Part A: Molecular and Biomolecular Spectroscopy, 177, 15-19.

VAnna, R. et al. (2015). Label-free imaging and identification of typical cells of acute myeloid leukaemia and myelodysplastic syndrome by Raman microspectroscopy. Analyst, 140 (4), 1054-1064.

Xie, Y. et al. (2020). In situ exploring Chidamide, a histone deacetylase inhibitor, induces molecular changes of leukemic T-lymphocyte apoptosis using Raman spectroscopy. Spectrochimica Acta Part A: Molecular and Biomolecular Spectroscopy, 241, 118669.

Zhang, d. et al. (2015). Raman spectrum reveals the cell cycle arrest of Triptolide-induced leukemic T-lymphocytes apoptosis. Spectrochimica Acta Part A: Molecular and Biomolecular Spectroscopy, 141, 216-22.

Zong, C. et al. (2018). Surface-enhanced Raman spectroscopy for bioanalysis: reliability and challenges. Chemical Reviews, 118 (10), $4946-4980$. 